\title{
Performance Assessment of Moratuwa- Ratmalana Biological Nutrient Removal Industrial Wastewater Treatment Plant
}

\author{
Danushika U.A.A.G. ${ }^{1 *}$, Bandara N.J.G.J. ${ }^{1}$ and Rupasinghe S.K.L.S. ${ }^{2}$ \\ ${ }^{I}$ Department of Forestry and Environmental Science, University of Sri Jayewardenepura, Sri Lanka \\ ${ }^{2}$ Research and Development Department, National Water and Drainage Board, Ratmalana, \\ Sri Lanka \\ *gdanushika20@gmail.com
}

\begin{abstract}
This study evaluates the performance of Moratuwa-Ratmalana Biological Nutrient Removal (BNR) plant during the dry period of 2016. This treatment plant is $1^{\text {st }}$ ever reverse $\mathrm{A}^{2} / \mathrm{O}$ (anoxic/ anaerobic/ aerobic) treatment plant in Sri Lanka which was established by the National Water and Drainage Board (NWDB) in 2013.

This study was confined to the dry period. This study was carried out to achieve two objectives. First objective is to monitor and evaluate the overall efficiency of the treatment plant in terms of removing pollutants from the influent. Second objective is to analyze nitrogen and phosphorous removing ability in each compartment.

Samples were collected weekly for a stretch of 15 weeks from February to May. The sampling method utilized in this study was 'grab sampling' and 'composite sampling'. First samples from each three layers of each of the three compartments were collected through grab sampling and then composite samples for each layer was prepared by using the grab samples. Composite samples were used for final testing. In addition samples were also collected for influent and effluent from the composite sampler which is located in the treatment plant.
\end{abstract}

The analysis was carried out to test for physical (pH, Temperature) and chemical (BOD, COD, TSS, TP, TN) parameters of each collected sample.

The performance evaluation has indicated that $88.52 \%$ COD removal, 97.05\% TSS removal, $94.12 \%$ BOD removal, $84.23 \%$ of TP removal and $81.65 \%$ of TN removal efficiencies have been achieved. Also the analytical measurements obtained of the treated effluent are compatible with the discharge water quality standards issued by CEA, Sri Lanka. In addition it was shown that each compartment of the treatment plant meets the design expectations regarding Nitrogen and Phosphorous removing abilities.

Keywords: Wastewater Treatment, Plant performance, Reverse $\mathrm{A}^{2} / \mathrm{O}$

Proceedings of the International Forestry and Environment Symposium 2016, Department of Forestry and Environmental Science, University of Sri Jayewardenepura, Sri Lanka. 